\title{
Oral treatment with Lactobacillus rhamnosus attenuates behavioural deficits and immune changes in chronic social stress
}

\author{
Aadil Bharwani ${ }^{1,2,3}$, M. Firoz Mian², Michael G. Surette ${ }^{4,5}$, John Bienenstock ${ }^{1,2}$ and Paul Forsythe $2,4,6^{*}$
}

\begin{abstract}
Background: Stress-related disorders involve systemic alterations, including disruption of the intestinal microbial community. Given the putative connections between the microbiota, immunity, neural function, and behaviour, we investigated the potential for microbe-induced gut-to-brain signalling to modulate the impact of stress on host behaviour and immunoregulation.

Methods: Male C57BL/6 mice treated orally over 28 days with either Lactobacillus rhamnosus (JB-1) ${ }^{\mathrm{TM}}$ or vehicle were subjected to chronic social defeat and assessed for alterations in behaviour and immune cell phenotype. $16 \mathrm{~S}$ rRNA sequencing and mass spectrometry were employed to analyse the faecal microbial community and metabolite profile.

Results: Treatment with JB-1 decreased stress-induced anxiety-like behaviour and prevented deficits in social interaction with conspecifics. However, JB-1 did not alter development of aggressor avoidance following social defeat. Microbial treatment attenuated stress-related activation of dendritic cells while increasing IL-10+ regulatory T cells. Furthermore, JB-1 modulated the effect of stress on faecal metabolites with neuroactive and immunomodulatory properties. Exposure to social defeat altered faecal microbial community composition and reduced species richness and diversity, none of which was prevented by JB-1.

Stress-related microbiota disruptions persisted in vehicle-treated mice for 3 weeks following stressor cessation.

Conclusions: These data demonstrate that despite the complexity of the gut microbiota, exposure to a single microbial strain can protect against certain stress-induced behaviours and systemic immune alterations without preventing dysbiosis. This work supports microbe-based interventions for stress-related disorders.
\end{abstract}

Keywords: Chronic social defeat, Microbiota, Behaviour, Immune system, Gut-brain axis, Psychiatric disease

\section{Background}

Stress-related disorders have their roots in nuanced interactions between genetic and environmental risk factors, resulting in complex and multifactorial etiologies. The cumulative physiological effect of stressors [1] causes the dysregulation of multiple host systems due to

\footnotetext{
* Correspondence: forsytp@mcmaster.ca

${ }^{2}$ McMaster Brain-Body Institute, The Research Institute of St. Joseph's

Hamilton, Hamilton, Canada

${ }^{4}$ Department of Medicine, McMaster University, The Brain-Body Institute, 50

Charlton Avenue East, T3302, Hamilton, Ontario L8N 4A6, Canada

Full list of author information is available at the end of the article
}

allostatic overload. The last decade has witnessed a growing interest in the potential contribution of gut-brain signalling to psychiatric disorders. Chronic severe stress is associated with inflammation and increased susceptibility to functional gastrointestinal conditions, and there is strong evidence for co-morbidity between gastrointestinal symptoms and psychiatric disorders [2-4]. Although precise biological mechanisms remain unclear, it is possible that such bidirectional associations in stress are at least partly a consequence of alterations in gut-brain signalling pathways due to a disrupted gut microbial community. The latter is complex and dynamic, harbouring $\sim 10^{13}$ 
bacterial cells that represent 3.3 million non-redundant genes, rivalling our human genome by at least two orders of magnitude [5]. The critical role of the gut microbial community in the regulation of diverse physiological functions, including immunity, is well established, and there is growing evidence of its influence on the central nervous system [6-8]. For instance, administration of specific bacterial strains decreases anxiety- and depressive-like behaviours $[9,10]$, while changes in the microbial community modulate stress-induced inflammation [11, 12]. The emergent corollary demonstrates the inextricable relationship between the microbiota, immune, and nervous systems, and their roles in regulating behaviour and neural function. Indeed, along with other groups, we have demonstrated the top-down effect of psychological stress on the structure and function of the microbiota, resulting in reduced species diversity and richness, an altered community profile, and shifts in functional pathways [12-14]. Given microbial regulation of host signalling at the mucosal interface between microbiota and host, disruptions in this community may lead to systemic changes in peripheral signals $[15,16]$. For instance, immune dysregulation has been implicated in psychological stressors and psychiatric disorders $[12,17]$. However, much remains to be determined regarding how bottom-up signalling along the gutbrain axis might be utilized to modulate stress-related changes in behaviour and neural function.

The aim of the present study was to investigate the role of microbe-induced gut-to-brain signalling on the central and systemic disruptions induced by chronic exposure to a psychosocial stressor. Using a validated model of chronic stress and depression [18, 19], we determined whether oral administration of a bacterium with neuroactive and immunomodulatory properties could modulate stress-induced behavioural deficits, immune changes, and gut dysbiosis. We selected Lactobacillus rhamnosus JB-1 $1^{\mathrm{TM}}$ (JB-1) as our test organism, as oral treatment with this strain was previously demonstrated to lead to changes in neurotransmitter levels in the brains of mice [20] and to have anxiolytic and antidepressant-like activity on baseline behaviours-effects dependent on an intact vagus nerve [10]. Feeding the JB1 strain also modulates enteric nervous system function [21], increases the frequency of vagal afferent firing [22], and has well-described anti-inflammatory and immunoregulatory effects [23-25]. To elucidate metabolites that may drive effects of bacteria on the brain, we investigated candidate functional pathways using metabolomics profiling. Furthermore, we examined the duration of stress-induced disruptions in the microbiota and the possibility of whether administration of a single bacterial strain during stress exposure can facilitate recovery of the dysbiotic community.

\section{Methods \\ Animals}

Male C57BL/6 mice, 8 weeks old, and CD-1 retired breeders were acquired from Charles River (Montreal, Canada). Animals were acclimatized for 7 days in standard conditions (12-h light-dark cycle) with ad libitum access to standard chow and water. All experiments followed Canadian Council on Animal Care guidelines and were approved by the McMaster Animal Research Ethics Board.

\section{Treatment and social defeat}

Animals were gavaged with $200 \mu \mathrm{l}\left(1.67 \times 10^{9} \mathrm{CFU}\right)$ of Lactobacillus rhamnosus (JB-1) ${ }^{\mathrm{nm}}-\mathrm{a}$ gift from Alimentary Health Ltd., Cork, Ireland-or equivalent volume of phosphate-buffered saline (PBS). Treatment was administered over 28 days, Monday to Friday, between 1 to 3 p.m. During the final 10 days of treatment (Fig. 1), chronic social defeat (CSD) was initiated as previously described (Additional file 1) [18]. For $24 \mathrm{~h}$ after each defeat, mice were housed in the same cage across a perforated Plexiglas divider from their aggressors.

\section{Behavioural testing}

Details of the behavioural testing are provided in Additional file 1 . Behavioural testing began $24 \mathrm{~h}$ after the final defeat session, and was recorded/analysed using Motor Monitor (Kinder Scientific) and EthoVision XT (Noldus). Anxiety-like and exploratory behaviours were assessed using the light-dark box test (LDT) and open field test (OFT). Sociability and susceptibility were assessed using the three-chamber sociability and aggressor approach-avoidance tests.

\section{Tissue analysis}

Mice were euthanized 5 days after the final defeat session. Spleens were harvested and dispersed using a cell strainer in cold, sterile PBS. Cell suspensions were centrifuged at $1500 \mathrm{rpm}$ for $10 \mathrm{~min}$ at $4{ }^{\circ} \mathrm{C}$, then resuspended in red blood cell (RBC) lysis buffer for 1$2 \mathrm{~min}$. The resulting solution was centrifuged before the cell pellets were washed with $5 \mathrm{ml}$ of complete RPMI 1640 medium: 10\% foetal bovine serum, penicillin/ streptomycin antibiotics, $2 \mathrm{mM} \mathrm{L-glutamine,} \mathrm{and} 0.01 \%$ $\beta$-mercaptoethanol. Viable cell numbers were assessed by Trypan Blue exclusion and diluted in RPMI to a concentration of $10^{7}$ cells $/ \mathrm{ml}$. Splenocytes $\left(10^{6}\right)$ were stained for markers of dendritic cell (DC) maturation and function-CD11c- PerCP-Cy5, MHCII-FITC, CD80-PE, and CD86-APC-or regulatory T cells-CD3-APC, CD4FITC, CD25-PE-Cy7, and intracellular IL-10-PE (BD Pharmingen, San Diego, CA, USA; eBioscience, San Diego, CA, USA). Following surface staining, cells were fixed and permeabilized with BD Cytofix/Cytoperm 


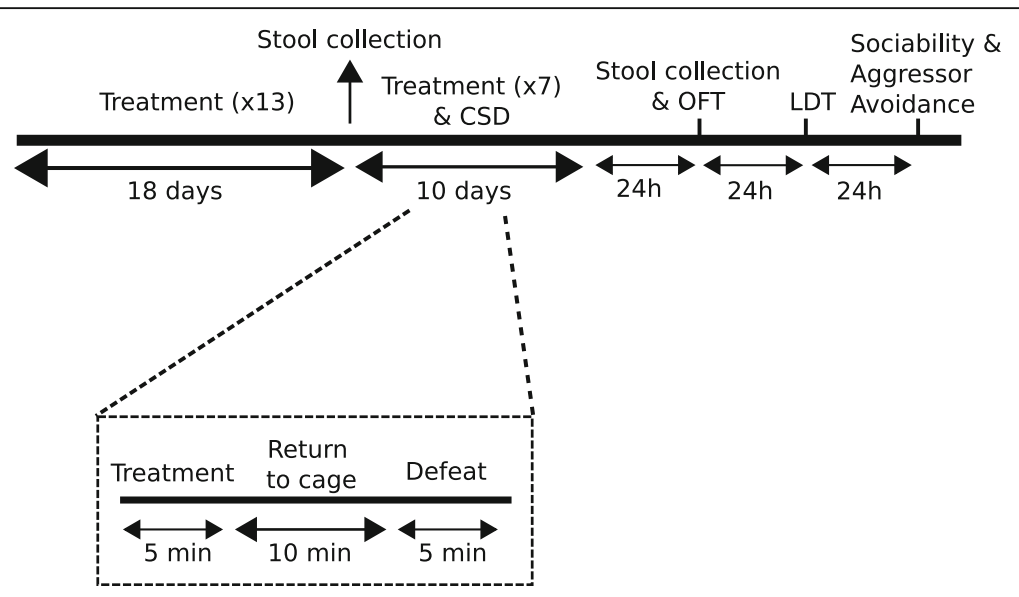

Fig. 1 Schematic diagram of experimental approach. Mice were treated with JB-1 on 20 instances over a period of 28 days, including 7 instances over the final 10 days, during which mice were exposed to chronic social defeat (CSD) stress every day. OFT open field test, LDT light-dark box test

before staining for intracellular markers. Data were acquired with FACSCanto (Becton Dickinson, Oakville, ON, Canada) and analysed using FlowJo (TreeStar, Ashland, OR, USA).

\section{RNA extraction and RT-qPCR analyses}

Following rapid decapitation, the frontal cortex and hippocampus were macrodissected using their stereotaxic coordinates according to the Mouse Brain Atlas and placed into RNAlater ${ }^{\ominus}$ solution (Ambion, Life Technologies, CA, USA). Tissues were incubated overnight at $4{ }^{\circ} \mathrm{C}$ and then transferred to $-20{ }^{\circ} \mathrm{C}$ storage to await further processing. RNA extraction was carried out using TRIzol $^{\oplus}$ Reagent (Ambion, Life Technologies) following manual homogenization. RNA quality was assessed using a NanoDrop ${ }^{\circledR}$ Spectrophotometer ND-1000. $1 \mu \mathrm{g}$ RNA was then converted into complementary DNA (cDNA) by using SuperscriptIII ${ }^{\mathrm{TM}}$ First-Strand Synthesis Supermix (Invitrogen, CA, USA). Diluted or non-diluted cDNA was used as a template for qPCR reaction using PowerUp $^{\text {тм }}$ SYBR $^{\oplus}$ Green Master Mix (Applied Biosystems, Life Technologies, Austin, TX, USA) containing ROX $^{\mathrm{Ts}}$ Passive Reference Dye. The qPCR reactions were performed in the fast mode (uracil-DNA glycosylase [UDG] activation $50{ }^{\circ} \mathrm{C}, 2 \mathrm{~min}$; Dual-Lock ${ }^{\mathrm{TM}}$ DNA polymerase $95{ }^{\circ} \mathrm{C}, 2 \mathrm{~min}$; denaturation $95^{\circ} \mathrm{C}, 1 \mathrm{~s}$; annealing/ extension $60{ }^{\circ} \mathrm{C}, 30 \mathrm{~s}$; number of cycles: 40) by using QuanStudio3 $^{\text {тм }}$ (Applied Biosystems). Primers were designed with Primer Express ${ }^{\mathrm{Tm}}$ Software and used at a concentration of $300 \mathrm{nM}$. Primer sequences are listed in Additional file 2: Table S6. Transcripts were normalized to endogenous glyceraldehyde-3-phosphate dehydrogenase (GAPDH) and quantified using the $\Delta \Delta \mathrm{Ct}$ method, with related fold change expressed as $2^{(-\Delta \Delta C t)}$

\section{S rRNA analysis and metabolomics}

Faecal pellets were stored at $-80{ }^{\circ} \mathrm{C}$. DNA extraction was carried out as previously described [13]. Bacterial community profiling of $16 \mathrm{~S}$ rRNA was carried out on a MiSeq Illumina sequencer in the McMaster Genome Center (McMaster University). Metabolite profiling was performed by Metabolon, Inc.

Using rarefied data in QIIME [26], Chao1 and phylogenetic diversity metrics were implemented, and Jackknife resampling was used to generate Bray-Curtis distances. (Dis)similarity between the groups was calculated using the Monte Carlo permutation procedure (MCPP) (999 permutations) and a priori Bonferronicorrected non-parametric $t$ tests. Kruskal-Wallis one-way analysis of variance (ANOVA) or the Mann-Whitney U test, followed by the Benjamini-Hochberg correction for multiple comparisons (false discovery rate, FDR $<0.05$ ), was used to analyse differential abundance of operational taxonomic units (OTUs) in groups.

\section{Statistical analysis}

Data were analysed in IBM's SPSS (version 22, Chicago) and GraphPad Prism 6 using a two-tailed Student's $t$ test, Mann-Whitney U test, or ANOVAs, with Bonferroni-corrected post hoc tests. Two-way ANOVAs with contrasts followed by Benjamini-Hochberg correction (FDR <0.1) were used to analyse metabolomics data. No statistical methods were used to predetermine sample sizes; however, $n$ values used herein are consistent with previous work. During the course of social defeat and testing, some animals were removed due to excessive wounding (open wounds exceeding $1 \mathrm{~cm}$, as per the Animal Utilization Protocol approved by McMaster's Animal Research Ethics Board). Results in figures are expressed as mean \pm standard error of the 
mean (SEM), where applicable. Statistical significance is denoted as $*(p<0.05),{ }^{* * *}(p<0.01)$, and ${ }^{* * * *}(p<0.001)$.

\section{Results \\ Microbial treatment modulates specific stress-induced behavioural deficits}

Chronic social defeat (CSD) reveals distinct phenotypes-susceptible and resilient-based on behaviour in the aggressor approach-avoidance test [18, 19, 27]. CSD induced expression of both phenotypes in either treatment group, with no difference in the proportion of resilient mice: $18.1 \%(6 / 33)$ of vehicle-treated defeated mice and $15.6 \%$ (5/32) of defeated mice treated with JB1 until CSD cessation. Only the susceptible group was used for all experiments.

We have previously demonstrated that mice subjected to CSD exhibit sociability deficits [13]. Vehicle-treated defeated mice (DEF/VEH) exhibited pronounced avoidance of the social chamber (group $\times$ chamber interaction $\left[F_{1,23}=5.438, p=0.029\right.$, post hoc, $\left.p<0.05\right]$ ) (Fig. 2b). However, defeated mice administered JB-1 (DEF/JB-1) demonstrated no preference between the social and non-social chambers (post hoc, $p>0.05$ ) (Fig. 2b) and, relative to $\mathrm{DEF} / \mathrm{VEH}$, exhibited a greater social:non-social ratio $\left(F_{1,39}=9.660, p=0.004\right.$, post hoc, $\left.p<0.05\right)$ (Fig. 2c), indicating a partial correction of stress-induced deficits in social behaviour. Notably, treatment did not alter baseline behaviour (Fig. 2a).

Susceptible mice markedly avoid interactions with a novel aggressor [18]. Thus, we investigated whether the positive effects of JB-1 extended to behaviour on the aggressor approach-avoidance test (Fig. 2d). DEF/JB-1 mice continued to exhibit pronounced avoidance of the zone surrounding the aggressor ('interaction zone') exclusively during the presence of the aggressor $\left(F_{1,23}=130.8\right.$, $p<0.0001$ ) (Fig. 2e).

Chronic social stress also induces anxiety-like behaviour and deficits in exploration $[13,28]$. On the OFT, stress decreased rearing behaviour $\left(F_{1,81}=131.2, p<0.0001\right)$, indicating reduced exploration. Simple effects analysis of defeated groups revealed that JB-1 significantly attenuated deficits in rearing $\left(F_{1,14}=6.888, p=0.02\right)$ (Fig. 2f). Overall, there was no main effect of treatment on rearing or locomotion. Neither stress exposure nor treatment influenced time spent in the center of the open field (Additional file 1: Figure S1B). On the LDT, both defeated groups exhibited fewer transitions into the light compartment $\left(F_{1,57}=36.34, p<0.0001\right)$, which is a more salient measure of anxiety-like behaviour [29] (Fig. 2 g). However, DEF/JB-1 mice ventured into the light compartment more frequently than DEF/VEH mice, indicating an anxiolytic-like effect of JB-1 administration (stress exposure $\times$ treatment interaction $\left[F_{1,57}=5.171, p=0.027\right.$, post hoc, $p<0.05])$. Neither stress nor treatment affected time spent in the light compartment (Additional file 3: Figure S1C).

Given the paucity of literature regarding the long-term ramifications on behaviour following cessation of interventions, we re-tested a subset of mice 3 weeks following CSD exposure and treatment cessation. Entries into the light compartment $24 \mathrm{~h}$ following the final defeat were significantly different between the $\mathrm{CON} / \mathrm{VEH}$ and $\mathrm{DEF} / \mathrm{VEH}$ groups, but not between the CON/VEH and DEF/JB-1 or DEF/VEH and DEF/JB-1 groups $\left(F_{1,26}=\right.$ 6.738, $p=0.004$, post hoc, CON/VEH versus DEF/VEH at $24 \mathrm{~h}, p<0.01)$, further corroborating the anxiolyticlike effects of JB-1 (Fig. $2 \mathrm{~h}$ ). Three weeks post-stressor, there were no significant differences between any of the three groups, indicating a recovery of stress-induced anxiety-like behaviour. Neither JB-1 nor time influenced aggressor avoidance behaviour 3 weeks post-stressor (Fig. 2i).

To investigate the neural mechanisms underlying the effect of microbial treatment on the expression of stressrelated behaviours, we examined changes in expression of genes related to the stress circuitry in the frontal cortex and hippocampus. Neither stress nor treatment altered the expression of corticotropin-releasing factor receptor type 1 or type 2 in the frontal cortex or the hippocampus, or the glucocorticoid receptor in the frontal cortex (Additional file 4: Figure S2A-E). Stress decreased the expression of glucocorticoid receptors in the hippocampus $\left(F_{1,16}=10.67, p=0.005\right)$-an effect that was not influenced by JB-1 treatment (Additional file 4: Figure S2F). Given that we have previously demonstrated the effects of JB-1 administration on central gamma-aminobutyric acid (GABA) receptors [10], we examined whether similar changes might underlie the effects of the bacteria in a chronic stress model. Stress reduced the expression of $\operatorname{GABA}_{\mathrm{A} \alpha 2}\left(F_{1,30}=6.126, p=0.019\right)$ and $\operatorname{GABA}_{\mathrm{B} 1 \mathrm{~b}}$ mRNA $\left(F_{1,30}=5.961, p=0.021\right)$ in the frontal cortex, in the absence of a treatment effect (Additional file 4: Figure S2G, H). There were no effects of either stress or treatment on $\mathrm{GABA}_{\mathrm{A} \alpha 2}$ or $\mathrm{GABA}_{\mathrm{A} \alpha 2}$ mRNA levels in the hippocampus (Additional file 4: Figure S2I, J).

These data demonstrate that microbial treatment partially corrects the adverse effects of stress on social preference, exploration, and anxiety-like behaviours.

\section{Microbial treatment regulates stress-induced alterations in the immune phenotype}

The immune system represents an important interface for bacteria-host signalling and has been hypothesized as a potential effector of gut-brain communication $[7,15]$. CSD increased the population of IL-10+ CD4+ CD25+ $\mathrm{T}$ cells $(\mathrm{CD} 3+) \quad\left(F_{1,16}=6.114, p=0.025\right) \quad$ (Fig. 3a). Microbial treatment alone similarly increased the population of these spleen-derived IL-10-expressing Tregs 

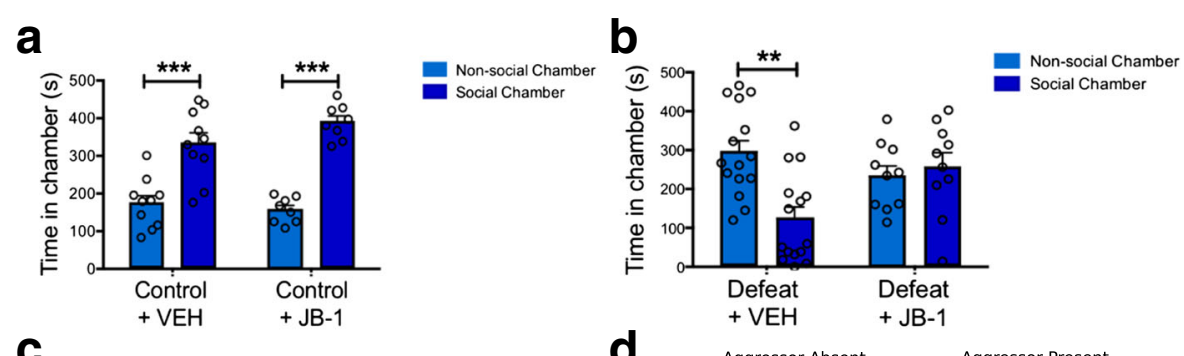

C

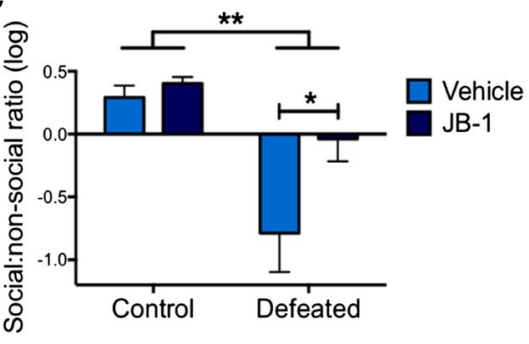

e

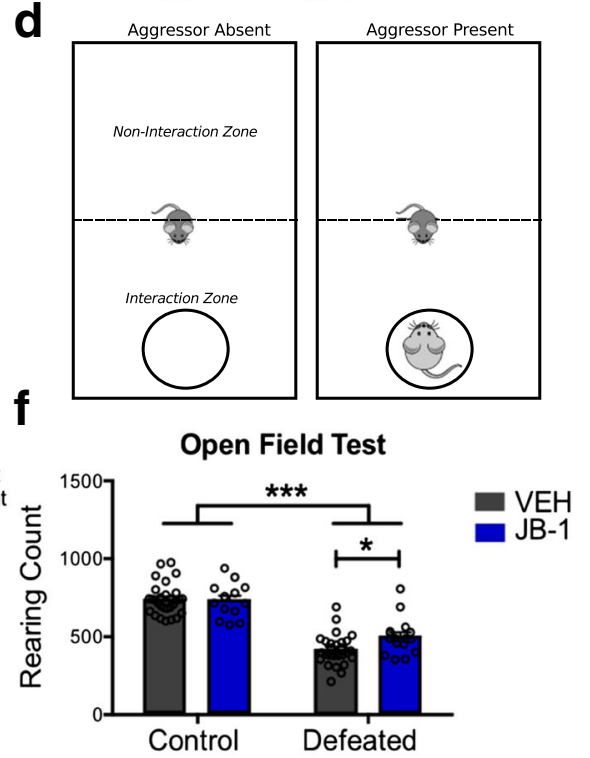

g Light Dark Test
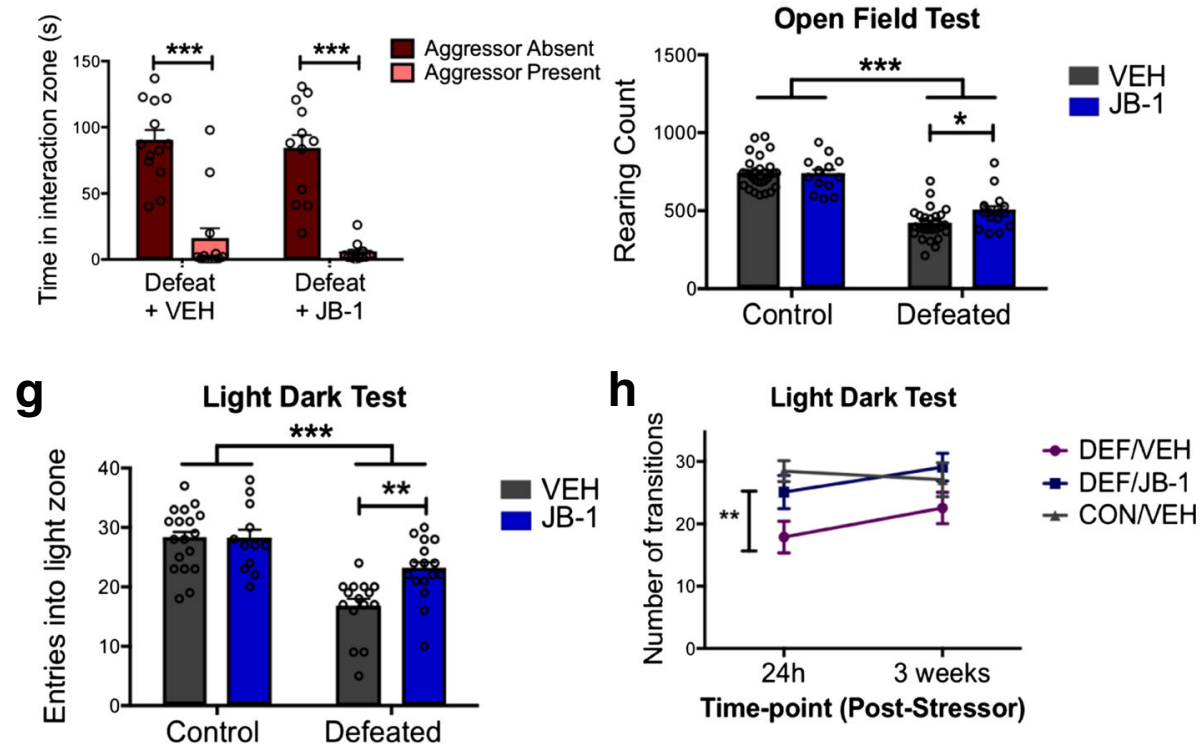

i

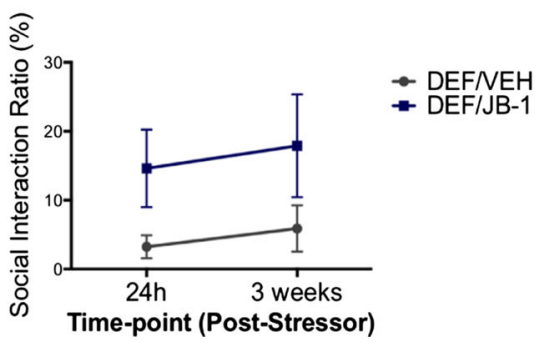

Fig. 2 (See legend on next page.) 


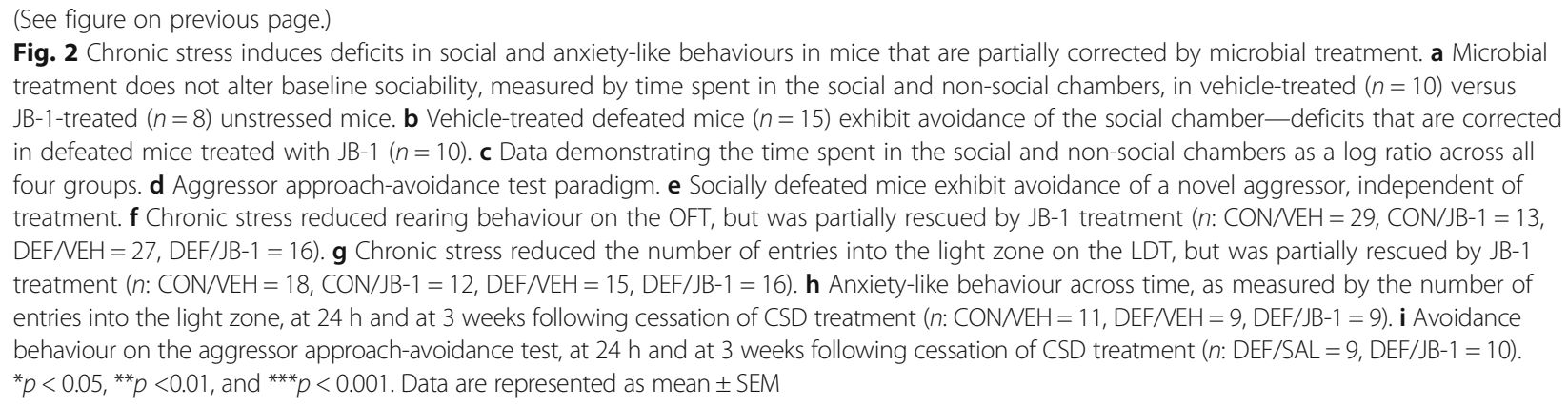

$\left(F_{1,16}=5.621, p=0.031\right)$. The immunomodulatory effects of JB-1 were not limited to adaptive immunity, as treatment also prevented the stress-induced increase in spleen-derived dendritic cells (MHCII+ CD11c+) expressing markers of activation, CD80 (stress exposure $\times$ treatment interaction $\left[F_{1,15}=8.224, p=0.012\right.$, post hoc, $p<0.05]$ ) and CD86, though the latter did not reach statistical significance (Fig. 3b, c).

This suggests that administration of JB-1 promoted systemic changes in the immunoregulatory phenotype and influenced the effects of chronic stress on host immunity.

\section{Microbial treatment does not prevent stress-induced dysbiosis of the microbiota}

Multiple groups have confirmed that stress induces dysbiosis $[12,13,30]$, correction of which can impart positive effects on the host $[31,32]$. Thus, we investigated whether JB-1 exerted its neurobehavioural effects on the stressed host by restoring the microbiota.

Prior to social defeat, although significantly greater levels of $L$. rhamnosus cells per gram of faeces were detected in mice administered JB-1 (Additional file 3: Figure S1D), JB-1 did not significantly alter the overall profile of the microbial community (Additional file 3: Figure S1E) or post-defeat body weight across groups. As previously described [13], exposure to CSD reduced the diversity $\left(F_{1,68}=13.21, p=0.0005\right)$ and richness $\left(F_{1,68}=12.50, p=0.0007\right)$ of the microbiota (Fig. 4a). These alterations were not ameliorated in DEF/JB-1 mice (post hoc, $p>0.05$ ). Assessment of community richness did reveal a significant stress exposure $\times$ treatment interaction: $\mathrm{CON} / \mathrm{JB}-1$ mice had a richer gut microbiota relative to CON/VEH mice $\left(F_{1,68}=5.616\right.$, $p=0.021$, post hoc, $p<0.05)$. However, there was no effect of treatment in the defeated groups (post hoc, $p>0.05$ ).

To compare group differences in the overall microbiota profile, Bray-Curtis distances (Fig. 4b) were analysed using a priori planned comparisons. Stress altered the microbiota profile: distances within non-defeated mice were smaller than distances between defeated and non-defeated mice (Fig. 4c; Additional file 2: Table S1;
Bonferroni-corrected non-parametric $p=0.013)$. JB-1 treatment did not prevent stress-induced changes in the microbiota: profiles within a group (within-DEF/VEH and within-DEF/JB-1) were not significantly closer than profiles from the opposing group (DEF/VEH versus $\mathrm{DEF} / \mathrm{JB}-1)$, indicating a lack of clustering due to treatment (Bonferroni-corrected non-parametric $p>0.05$ ). Moreover, JB-1- and vehicle-treated non-defeated mice formed a separate cluster from DEF/JB-1 mice (Bonferroni-corrected non-parametric $p=0.013$ ).

We investigated whether microbial treatment restored the relative abundance of specific OTUs that discriminated defeated mice from the non-defeated controls. Eighteen OTUs (11 Bacteroidetes, 6 Firmicutes, 1 Proteobacteria) were altered by stress exposure $(q<0.05)$ (Additional file 2: Table S2), none of which were restored by JB-1 treatment.

Alterations in the major microbial phyla-Firmicutes and Bacteroidetes-are associated with dysbiosis and disease [33-36]. However, there was no effect of treatment on the Bacteroidetes/Firmicutes ratio (Fig. 4d). Together, these data suggest that JB-1 treatment failed to prevent stress-induced alterations to the microbiota community.

\section{Stress-induced dysbiosis persists for at least 3 weeks}

There is growing evidence from human reports indicating co-morbidity between psychiatric conditions such as depression and post-traumatic stress disorder (PTSD) and gastrointestinal disorders, which are associated with persistent dysbiosis [37]. Thus, 3 weeks following the cessation of CSD, we examined the endurance of stressinduced microbial disruptions and the possibility of whether treatment facilitated recovery.

Group differences due to stress exposure were still evident at this time point (analysis of similarities [ANOSIM], $\mathrm{R}=0.1307, p=0.009$ ). Within-group distances in $\mathrm{CON} / \mathrm{VEH}$ were smaller than the distances versus DEF/ $\mathrm{VEH}$ mice, indicating separation of CON/VEH and DEF/VEH groups due to stress exposure (Fig. 4e; Additional file 3: Figure S1F; Additional file 2: Table S1 [Bonferroni-corrected non-parametric $p=0.022]$ ). There 

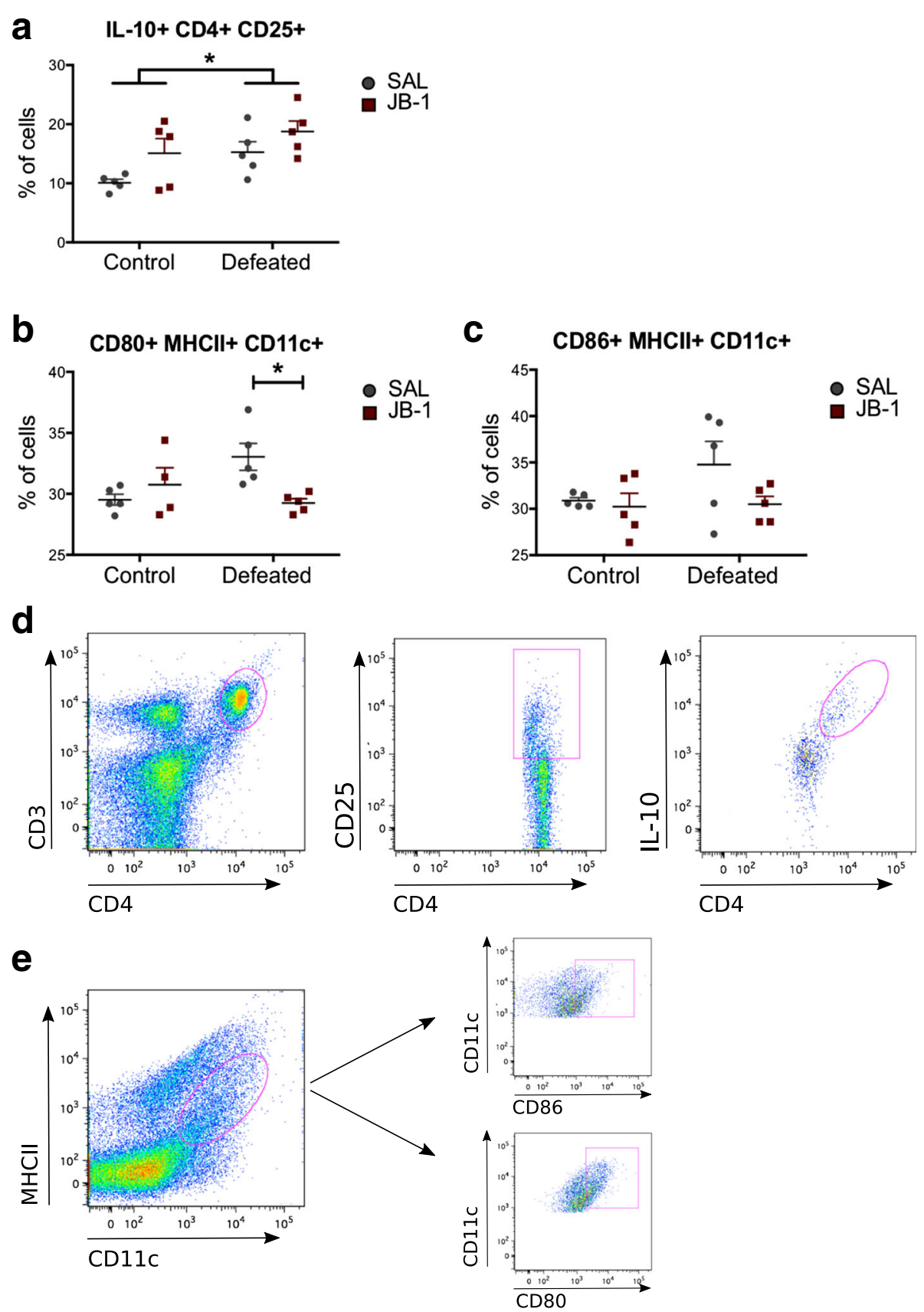

Fig. 3 Effect of chronic social defeat stress and JB-1 treatment on splenocyte phenotype ( $n=5 /$ group). a IL-10+ CD4+ CD25+ T cells in mice following exposure to chronic social defeat and JB-1 treatment. b JB-1 treatment prevents the stress-induced increase in CD80+ MHCII+ CD11C + splenocyte levels in defeated mice c CD86+ MHCII+ CD11c + splenocytes in mice following exposure to chronic social defeat and JB-1 treatment. d Fluorescence-activated cell sorting (FACS) gating strategy for IL-10+ CD4+ CD25+ T cells (CD3+). e FACS gating strategy for CD80+ and CD86+ on $\mathrm{MHCII+DCs}(\mathrm{CD} 11 \mathrm{c}+)^{*} p<0.05$. Data are represented as mean $\pm \mathrm{SEM}$

was no statistically significant difference between vehicle- and JB-1-treated defeated mice.

Similarly, comparison of community diversity and richness at the 3 -week time point indicated differences only between the CON/VEH and DEF/VEH groups (Fig. 4f, phylogenetic diversity, $F_{2,28}=7.893$, $p=0.002$; Chao1 richness, $F_{2,28}=6.061, p=0.007$ ). Thus, these data indicate that social defeat-induced dysbiosis persisted for at least 3 weeks following stress exposure and the defeat-induced change in microbiome profile was not significantly altered by JB-1 treatment. 

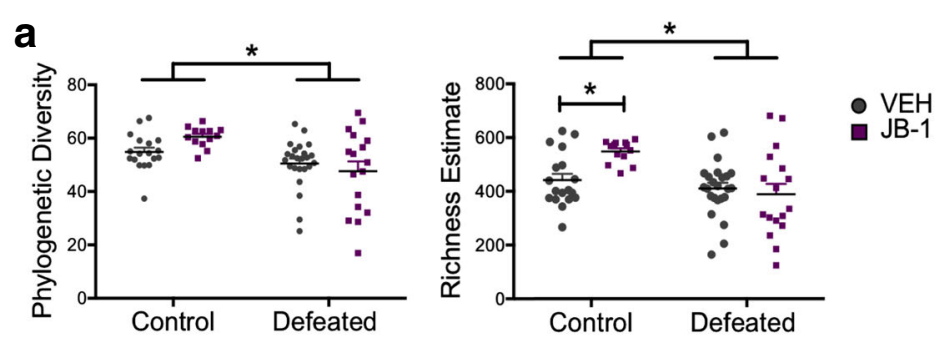

b

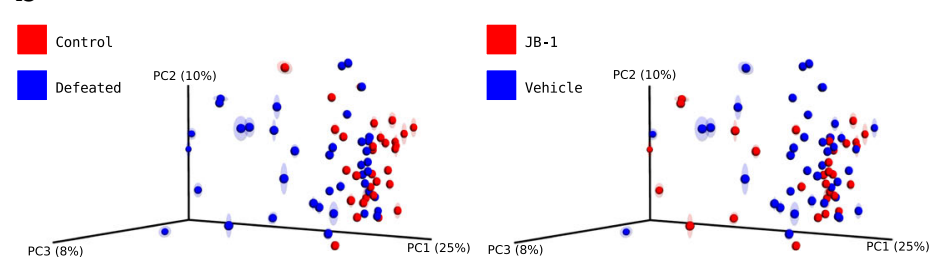

C

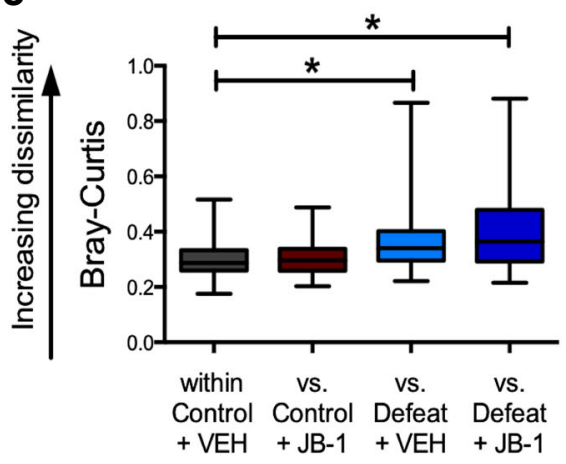

d

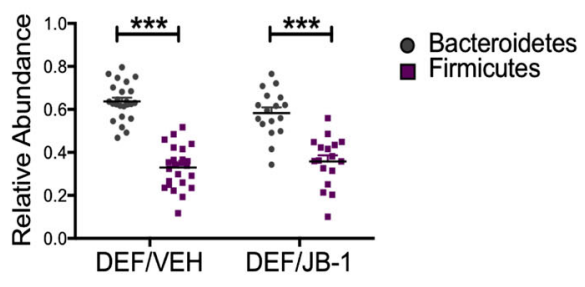

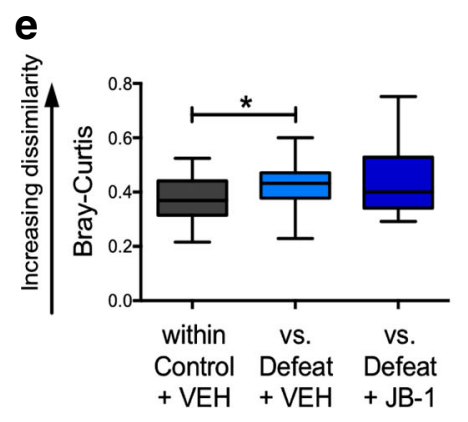

f
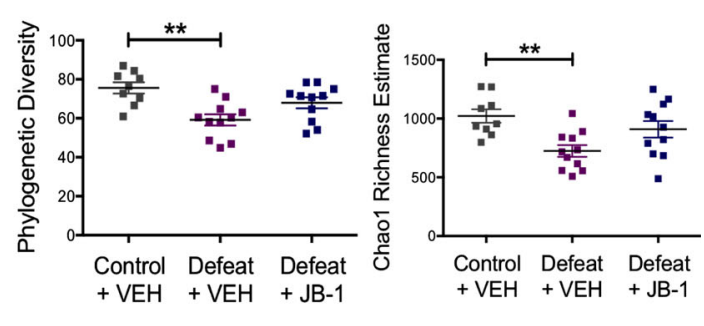

Fig. 4 JB-1 treatment does not affect stress-induced structural changes in the microbiota community. a Effect of chronic social defeat and JB-1 treatment on phylogenetic diversity and Chao 1 richness estimates from the rarefied $16 \mathrm{~S} r \mathrm{RNA}$ data $(n: \mathrm{CONNEH}=18, \mathrm{CON} / \mathrm{JB}-1=13, \mathrm{DEF} \mathrm{NEH}=24$, DEF/JB-1 = 17, 7923 reads/sample). b, c Principle coordinates analysis (PCOA) of Bray-Curtis distances from the average rarefied 16S rRNA data ( $n$ : CON/ $\mathrm{VEH}=18, \mathrm{CON} / \mathrm{JB}-1=13, \mathrm{DEF} / \mathrm{EH}=24, \mathrm{DEF} / \mathrm{JB}-1=17 ; n=999$ rarefactions, 6339 reads/sample) indicate a significant effect of social defeat on group clustering ( $p=0.013$ ), but no effect of JB-1 treatment (median $\pm \mathrm{min} / \mathrm{max}$ ). $\mathbf{d}$ Effect of chronic social defeat and JB-1 treatment on the taxonomic distribution of OTUs at the phylum level ( $n=17-24 /$ group). e Bray-Curtis distances from the average rarefied 165 rRNA data ( $n=999$ rarefactions, 44,648 reads/sample) three weeks after stressor and treatment cessation indicate a persistent significant effect of social defeat on group clustering ( $p=0.022$ ), but no difference between the control group and defeated mice treated with JB-1 (median \pm min/max). f Phylogenetic diversity and Chao 1 richness estimates from the rarefied $16 \mathrm{~S}$ rRNA data (55,810 reads/sample) 3 weeks after stressor and treatment cessation indicate a persistent significant effect of social defeat, but no difference between the control group and defeated mice treated with JB-1 ( $n=9-11 / g$ roup). ${ }^{*} p<0.05$, ${ }^{* *} p<0.01$, and ${ }^{* * *} p<0.001$. Data are represented as mean \pm SEM unless otherwise indicated 
The faecal metabolome is altered by exposure to chronic psychosocial stress and $L$. rhamnosus JB-1 treatment

Host and microbial metabolites play a contributory role in health and disease, including neural development and behaviour [16]. A total of 621 metabolites were detected in the faeces of mice; 70 were significantly altered by stress exposure $(q<0.1)$, many of which were associated with pathways previously predicted using in silico techniques: synthesis and metabolism of fatty acids, and tryptophan and tyrosine metabolism (Additional file 2: Table S3) [13]. Furthermore, 75 faecal metabolites were regulated by JB-1 treatment (Additional file 2: Table S4).

Previous work has demonstrated that JB-1 signals the brain via the vagus nerve $[10,22,38]$. To investigate signals that play a role in JB-1-driven vagal signalling, we explored for metabolites that were elevated exclusively in JB-1-treated stressed mice; however, no such metabolites were detected $(q<0.1)$.

We investigated functional pathways that were altered by exposure to CSD, but not in JB-1-treated mice. This criterion $(q<0.1)$ yielded 15 metabolites (Fig. 5a, b; Additional file 2: Table S5), including 1-methylnicotinamide-a vitamin B3 derivative with anti-inflammatory effects [39]-and 4-hydroxybutryrate (GHB), a metabolite with neurotransmitter-like effects [40-42]. Other metabolites meeting this criterion include glutarate, $N$-acetylcitrulline, glycerate, lactobionate, 3-hydroxybutyrylcarnitine, 10hydroxystearate, multiple metabolites derived from sphingolipid metabolism, alpha-muricholate, and lithocholate. However only for one metabolite that met this criteria, tyramine, a monoamine with sympathomimetic properties $[43,44]$, did the difference between DEF/VEH and DEF/ JB-1 reach statistical significance (Fig. 5c).

Stress increased the levels of kynurenine in both groups of defeated mice $\left(F_{1,31}=5.839, \quad p=0.022\right)$ (Fig. 5d). Planned post hoc analysis revealed significant differences between vehicle-treated defeated and control groups $(p<0.05)$ but none between JB-1-treated control and defeated mice $(p>0.05)$. Neither stress nor microbial treatment affected the kynurenine/tryptophan ratio-a sensitive estimate of cellular immunity $[45,46]$.

These data demonstrate that CSD alters the levels of various faecal metabolites, some of which possess immunomodulatory and neuroactive properties, and that JB-1 treatment may modulate some of these changes.

\section{Discussion}

Using a validated model of chronic stress and depression $[18,19]$, we demonstrate, for the first time, the influence of a single orally administered bacteria strain, Lactobacillus rhamnosus JB-1, on behavioural deficits and systemic immune alterations caused by chronic exposure to a psychosocial stressor. While we observed no effects on baseline behaviour, JB-1 attenuated stress-induced behavioural deficits, including changes in sociability and anxiety-like behaviour, and prevented immunoregulatory alterations associated with the stress phenotype. Notably, the tempering of stress-induced changes occurred in the absence of any effects of treatment on stress-related disruptions in the microbiota, suggesting that JB-1 directly
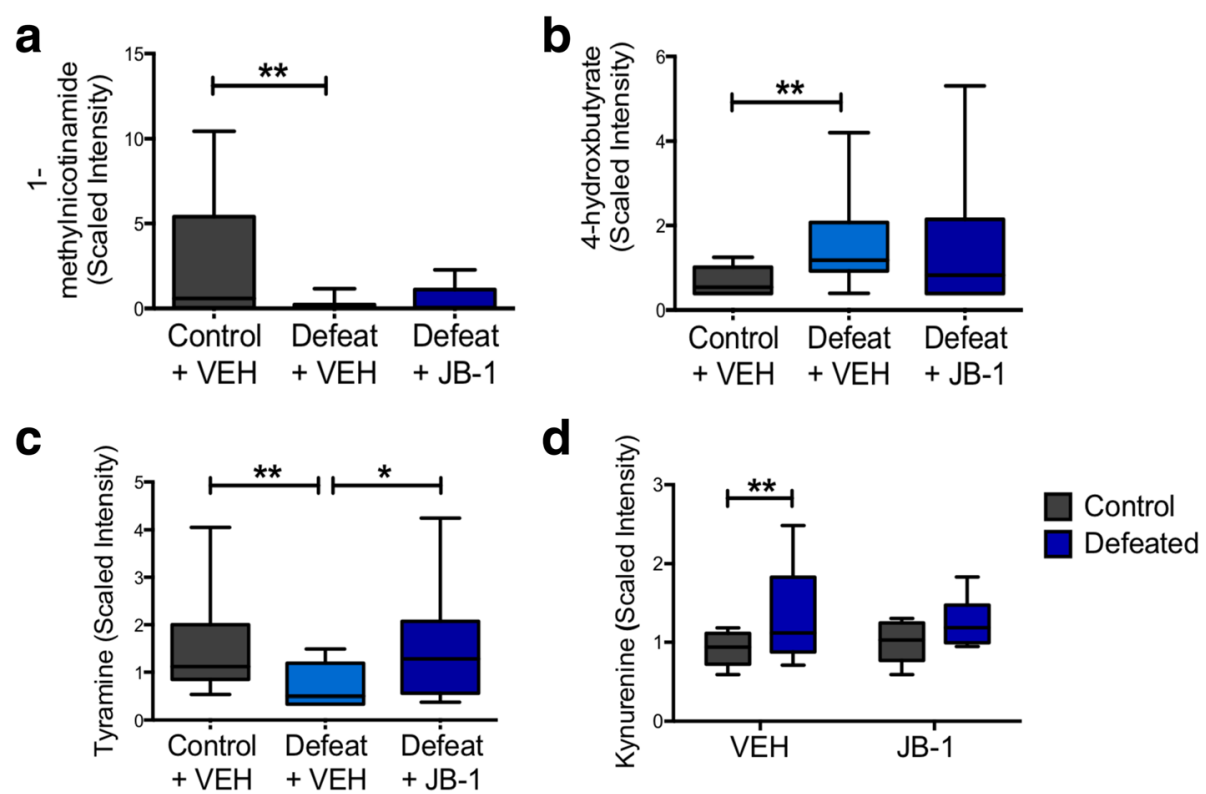

Fig. 5 Effect of chronic stress and JB-1 treatment on the faecal metabolome. a-d Metabolites whose levels were altered by chronic stress but prevented in JB-1-treated mice ( $n$ : CONNEH =10, CON/JB-1 =5, DEF/NEH=10, DEF/JB-1 = 10). a 1-methylnicotinamide, b 4-hydroxybutryrate, c tyramine, $\mathbf{d}$ kynurenine. ${ }^{*} p<0.05,{ }^{* *} p<0.01$. Data are represented as median $\pm \mathrm{min} / \mathrm{max}$ 
modulates gut-brain signalling pathways independently of the microbial community.

Following CSD, JB-1-treated stressed mice, as opposed to vehicle-treated, did not show avoidance of novel social stimuli, exhibited more frequent rearing behaviour in the OFT, and showed reduced aversion towards the light chamber (LDT). These data support the emerging literature suggesting that administration of specific bacterial strains decreases anxiety- and depressive-like behaviours $[9,10]$. Indeed, we have previously demonstrated that chronic administration of JB-1 in Balb/C mice altered baseline levels of anxiety-like behaviour [10]. That the effects of JB-1 here were limited to deficits produced by chronic stress and not baseline behaviour (Fig. 2), may be indicative of intrinsic differences between Balb/c and C57BL/6 mice, the latter of which exhibit reduced apprehension, neophobia, and anxietylike behaviour on baseline behavioural assays [47]. These mouse strain-specific effects may have implications for translational studies in humans, suggesting that, in keeping with a recent report [48], JB-1 would not be expected to have an anxiolytic effect in non-anxious individuals. Similarly, anti-depressants have very limited effects on healthy subjects [49].

In models of psychiatric conditions, repeated aggression and defeat lead to persistent conditioned submissive behaviour and aversion towards social stimuli $[18,50]$. These behavioural manifestations bear similarity to symptoms of social withdrawal in depression and phobic avoidance of trauma-related stimuli in PTSD [51]. It is notable that the ameliorating effects of JB-1 on deficits in social behaviour were limited to interactions involving a non-threatening conspecific, while avoidance of the novel trauma-related stimulus was maintained. Previous research has suggested dissociation of social and nonsocial forms of anxiety-like behaviour [52]. For instance, treatment with a human commensal organism, Bacteroides fragilis, in a model of autism spectrum disorder attenuated deficits in anxiety-like behaviour, but did not affect sociability [31]. Our findings suggest that social anxiety may be further dissociated into discrete, differentially modulated behaviours expressed towards nonthreatening versus threatening stimuli, the latter of which is experience-dependent $[18,19]$. Thus, the disparate effects of JB-1 on behaviours expressed by defeated mice may be due to independent underlying neural circuitry. Such dissociable circuitry has been indicated by work on the stimulation of nucleus accumbens afferents, which alters behaviour towards a novel aggressor, but not anxiety-like behaviour [27]. This concept is further supported and emphasized in the current study given the recovery of anxiety-like behaviour but not of aggressor avoidance behaviour 3 weeks post-defeat (Fig. $2 \mathrm{~h}$, i). In addressing neural mechanisms underlying the effect of microbial treatment on the expression of stress-related behaviours, we examined a limited number of genes related to the stress circuitry in the frontal cortex and hippocampus. While stress exposure reduced GABA receptor expression in the prefrontal cortex and glucocorticoid receptor expression in the hippocampus, there was no effect of microbe treatment on these measures. This contrasts the previously demonstrated effects of JB-1 administration on baseline expression of central GABA receptors in Balb/c mice [10]. While these results further emphasize the mouse strain-dependent effects of microbe exposure on gut-brain signalling, a more extensive assessment of additional neural pathways in multiple brain regions will be required to identify potential circuitry involved in JB-1-induced attenuation of stress-related behaviour.

Consistent with the immunomodulatory role of gut bacteria [15] and previous studies with JB-1 [24], microbial treatment influenced systemic changes in the CSDinduced immune phenotype. Social defeat increased the population of activated splenic DCs-a shift completely prevented by JB-1. Furthermore, treatment with the bacteria induced systemic expansion of Treg: a population that produces high levels of the anti-inflammatory cytokine, IL-10 [53]. Coordination between multiple host systems-and dysregulation thereof-likely contributes to the phenotypic changes in stress and related psychiatric conditions, during which systemic disruptions and allostatic load accumulate over extended periods of time. For instance, a pro-inflammatory milieu and a decrease in Tregs are commonly observed in severe stress and PTSD $[17,54]$ and form the central premise of the inflammation theory of depression [55]. Indeed, stressinduced trafficking of peripheral monocytes to the brain appears to play a crucial role in anxiety-like behaviour [56]. Disruption of the host-microbiota relationship during chronic stress may contribute to exaggerated inflammation and immune dysregulation and is associated with colitis and inflammatory bowel disease $[11,57]$. The observed acute increase in the Treg population (Fig. 3a) [13] following stress may be a counteractive response to the pro-inflammatory shifts described in the literature upon stress induction $[13,56,58]$; such responses are a well-documented reaction to host inflammation in an attempt to restore homeostasis [59]. Although this natural allostatic mechanism does not prevent an inflammatory environment during maladaptive stress, JB-1-induced modulation of host-initiated immunoregulatory responses may be one mechanism contributing to the behavioural effects of the bacteria. Similar mechanisms were posited to explain the stress-mitigating effects of Mycobacterium vaccae immunization, which were demonstrated to depend on Tregs [11]. These data suggest 
that recruitment of immune pathways in bottom-up (gut-to-brain) signalling is important. The current study was limited to two immune cell lineages: dendritic cells and $\mathrm{T}$ cells. Clearly, additional immune cell types may make important contributions to gut-brain signalling. Future studies should include a broader assessment of the immune system and more detailed examination of microbiota-immune-neural coordination and dysregulation of these systems in stress.

It has been proposed widely that modifying the resident intestinal bacteria in disease can reverse microbial dysbiosis and restore homeostatic function [60, 61]. Such an approach is especially relevant given evidence of microbiota disruption in severe stress and psychiatric conditions and its association with adverse gastrointestinal outcomes [37]. Thus, we investigated whether the improved neurobehavioural phenotype due to microbial treatment was associated with alterations to the existing microbiota community. Prior to stress exposure, administration of JB-1 did not alter the profile of the microbiota-data that parallel observations in humans who were administered a different strain of L. rhamnosus [62]. Furthermore, in our study, microbial treatment did not prevent any of the shifts in the microbiota community due to stress exposure. JB-1 treatment also completely failed to restore the diversity and richness of the microbiota or correct the relative abundances of specific OTUs altered by stress. Thus, the neuroactive properties of the beneficial microbe may be mediated independently of restoring microbial community balance, and might be dependent on its functional activity and direct modulation of host signalling pathways.

Not unexpectedly, the stress-induced dybiosis was accompanied by a significant change in levels of various faecal metabolites, while, perhaps more surprisingly, JB1 treatment alone significantly modulated the levels of 75 metabolites, many of which have immunomodulatory and neuroactive properties. While the source of these metabolites, host or microbe, cannot be identified, these observations suggest that JB-1 could alter the function of the existing gut microbiota without influencing composition. Most notably, the reduction in tyramine levels induced by CSD was the only metabolite change significantly inhibited by JB-1 treatment. Tyramine is a monoaminergic neuromodulator, acting as an agonist for trace amine-associated receptor 1 (TAAR1) [63]. Tyramine also causes the release of norepinephrine from sympathetic nerves, reversing re-uptake through the norepinephrine transporter and has been demonstrated to induce serotonin $(5-\mathrm{HT})$ production by enterochromaffin cells [64]. Given that intestinal 5-HT [65] and catecholamines [66] have been proposed as mediators of microbe-gut-brain signalling via modulation of the enteric nervous system, the impact of luminal tyramine levels on the gut-brain axis may warrant further investigation. The current study focused on faecal metabolites, with the understanding that gut lumen metabolites acting at the level of the gut epithelium, enteroendocrine cells, and enteric nervous system may play a role in microbe-gut-brain signalling. However, future assessment of plasma metabolites may identify circulating factors, produced by gut microbes or induced in the host, which have more direct effects on the central nervous system.

One limitation of the current study is that we only assessed the faecal microbiota, and it is possible that JB1 stabilized site-specific microbiota, for example, in the small intestine or specifically associated with the epithelium elsewhere, that are involved in gut-brain signalling. However, a direct action of JB-1 on gut-brain signalling is further supported by previous studies using in vivo and ex vivo models, demonstrating that it can directly or indirectly activate the vagus nerve and that an intact vagus is required to mediate the effects of this bacterium, at least on the baseline behaviour of Balb/c mice [22]. Collectively, these data suggest that JB-1, independently of changes in the microbiota, can recruit host signalling pathways, likely including vagal afferents that mediate the effects of the bacteria on severe CSDinduced neurobehavioural changes. Investigation of the role of the vagus in mediating microbe-induced modulation of behaviour in the CSD model is certainly warranted.

Although numerous studies have demonstrated the effect of environmental adversity on disruption of gut microbiota [11-13], there is very little evidence on the permanence of these changes in stress-related disorders or on whether microbial supplementation can facilitate the recovery of dysbiosis. A limited number of observations suggest a complex relationship between environmental factors and perturbations of the gut microbiota. Certain factors impart transient changes in the community, while others, for instance, antibiotic usage, leave behind a more persistent signature [67, 68]. Furthermore, factors such as birth delivery mode have marked effects on the microbiota community during early life that are no longer distinguishable in adulthood [69]. Our own observations suggest that stress-induced disruptions in the microbiota appear stable for a prolonged period following stress exposure. Examination of defeated mice 3 weeks following CSD revealed enduring structural changes in the faecal microbial community: defeated mice continued to show reduced diversity and richness in the variety of species represented while exhibiting broad-scale changes in overall composition and profile. The long-term stressinduced changes in the microbiome were not significantly altered with JB-1 treatment. 


\section{Conclusions}

There have been increasing efforts to understand how large-scale disruptions and dynamic shifts in gut microbiota can drive phenotypic changes and disease states [70]. This study represents a series of findings that further clarify the role of gut bacteria on neural function and behaviour. Although there continue to exist major gaps in our understanding of how disruptions in the microbiota contribute to neuropsychiatric conditions, the emerging theme underscores the intricate interactions between these systems in health and disease. While the current study did not delineate a mechanism of action of JB-1 in attenuating stress-induced behavioural changes, the results suggest that a more detailed investigation of immunomodulation and neural circuitry will likely provide valuable mechanistic insights. Furthermore, despite the complexity of the observed structural and functional changes in the microbial consortia, our data indicate that restoration of homeostasis can be facilitated using a single microbial strain. Given the diversity and inter-individual variability of the human gut microbiome [71-73], we propose that microbialbased interventions that bypass the microbiota to directly affect the host may possess greater therapeutic potential for the effective treatment of psychiatric conditions, or as an adjunct to current approaches.

\section{Additional files}

Additional file 1: Supplementary information. (DOCX $30 \mathrm{~kb}$ )

Additional file 2: Supplementary Tables: Table S1. Statistica comparisons of Bray-Curtis distances between a priori groupings. Related to Figure 4. Table S2. discriminatory OTUs between undefeated vehicle- and JB-1-treated controls, and vehicle- and JB-1-treated defeated mice. Related to Figure 4. Table S3. fecal metabolites altered in response to stress. Table S4. Main effect of $L$. rhamnosus (JB-1) treatment on fecal metabolites. Table S5. fecal metabolites altered by stress (DEFNEH vs CON/VEH) but unaffected in DEF/JB-1 vs CON/VEH. Related to Figure 5. Table S6. Primer sequences used for real time quantitative PCR. Related to Figure S2. (XLSX $83 \mathrm{~kb}$ )

Additional file 3: Figure S1. (A) Three-chamber sociability test paradigm. (B, C) Effect of chronic social defeat stress and JB-1 treatment on time spent in the center of the OFT and in the light chamber of the LDT. (D) Effect of JB-1 administration on detected levels of Lactobacillus rhamnosus cells in faecal samples. (E) Principle coordinates plots $(P C O A)$ of Bray-Curtis distances from the average rarefied $16 \mathrm{~S}$ rRNA data ( $n=999$ rarefactions, 52,182 reads/sample) indicate no effect of JB-1 treatment after 18 days, prior to initiation of chronic social defeat stress. (F) Related to Fig. 4e: principle coordinates plots (PCOA) of Bray-Curtis distances from the average rarefied $16 \mathrm{~S}$ rRNA data ( $n=999$ rarefactions, 44,648 reads/sample) 3 weeks after stressor and treatment cessation indicate a persistent significant effect of social defeat on group clustering $(p=0.022)$, but no difference between the control and DEF/JB-1 groups. (PDF $206 \mathrm{~kb}$ )

Additional file 4: Figure S2. (A-J). Effect of chronic social defeat stress and JB-1 treatment on gene expression levels in the frontal cortex ( $n=5-13 /$ group) and the hippocampus ( $n=4-8 /$ group). (PDF $258 \mathrm{~kb}$ )

\section{Acknowledgements}

The authors would like to gratefully acknowledge Alimentary Health for their generous gift of Lactobacillus rhamnosus JB-1 bacteria and Dr. Andrew Stanisz at the McMaster Brain-Body Institute for the preparation of bacterial treatments. The authors would also like to acknowledge Prof. Laure Bindels at the Université catholique de Louvain, Brussels, Belgium for the estimation of faecal content of L. rhamnosus.

\section{Funding}

This research was funded by a grant from the Office of Naval Research (N00014-14-1-0787). MGS is supported as a Canada Research Chair.

\section{Availability of data and materials}

The datasets used and/or analysed during the current study are available from the corresponding author on reasonable request.

\section{Authors' contributions}

$P F, J B$, and $A B$ conceptualized the study and designed the experiments. $A B$ performed all animal experiments. $A B$ and MFM prepared the samples and carried out FACS analysis. MGS performed 165 rRNA DNA sequencing. $A B$ acquired and analysed the data and wrote the initial draft of the manuscript. $A B, M F M, M G S, J B$, and PF contributed to data interpretation; PF revised the manuscript. All authors approved the final version of this article.

\section{Competing interests}

The authors report no biomedical financial interests or potential conflicts of interest. The sponsors had no role in the study design, the collection, analysis, or interpretation of data, the writing of the report, or the decision to submit the article for publication.

\section{Consent for publication \\ Not applicable.}

\section{Ethics approval}

All experiments followed Canadian Council on Animal Care guidelines and were approved by the McMaster Animal Research Ethics Board.

\section{Author details}

${ }^{1}$ Department of Pathology \& Molecular Medicine, McMaster University, Hamilton, Canada. ${ }^{2}$ McMaster Brain-Body Institute, The Research Institute of St. Joseph's Hamilton, Hamilton, Canada. ${ }^{3}$ Michael G. DeGroote School of Medicine, McMaster University, Hamilton, Canada. ${ }^{4}$ Department of Medicine, McMaster University, The Brain-Body Institute, 50 Charlton Avenue East, T3302, Hamilton, Ontario L8N 4A6, Canada. ${ }^{5}$ Farncombe Family Digestive Health Research Institute, McMaster University, Hamilton, Canada. ${ }^{6}$ Firestone Institute for Respiratory Health, St. Joseph's Healthcare Hamilton, Hamilton, Canada.

Received: 15 October 2016 Accepted: 15 December 2016

Published online: 11 January 2017

References

1. McEwen BS. Protective and damaging effects of stress mediators. N Engl J Med Mass Med Soc. 1998;338:171-9.

2. Duffy LC, Zielezny MA, Marshall JR, Byers TE, Weiser MM, Phillips JF, et al. Relevance of major stress events as an indicator of disease activity prevalence in inflammatory bowel disease. Behav Med. 1991;17:101-10.

3. Stam R, Akkermans LM, Wiegant VM. Trauma and the gut: interactions between stressful experience and intestinal function. Gut. 1997:40:704.

4. Klooker TK, Braak B, Painter RC, de Rooij SR, van Elburg RM, van den Wijngaard RM, et al. Exposure to severe wartime conditions in early life is associated with an increased risk of irritable bowel syndrome: a populationbased cohort study. Am J Gastroenterol. 2009;104:2250-6.

5. Ley RE, Peterson DA, Gordon Jl. Ecological and evolutionary forces shaping microbial diversity in the human intestine. Cell. 2006;124:837-48.

6. Forsythe P, Kunze WA. Voices from within: gut microbes and the CNS Cell Mol Life Sci. 2013;70:55-69.

7. Collins SM, Surette M, Bercik $P$. The interplay between the intestinal microbiota and the brain. Nat Rev Microbiol. 2012;10:735-42.

8. Cryan JF, Dinan TG. Mind-altering microorganisms: the impact of the gut microbiota on brain and behaviour. Nat Rev Neurosci. 2012;13:701-12. 
9. Bercik P, Denou E, Collins J, Jackson W, Lu J, Jury J, et al. The intestinal microbiota affect central levels of brain-derived neurotropic factor and behavior in mice. Gastroenterology. 2011;141:599-609.

10. Bravo JA, Forsythe P, Chew MV, Escaravage E, Savignac HM, Dinan TG, et al. Ingestion of Lactobacillus strain regulates emotional behavior and central GABA receptor expression in a mouse via the vagus nerve. Proc Natl Acad Sci. 2011;108:16050-5.

11. Reber SO, Siebler PH, Donner NC, Morton JT, Smith DG, Kopelman JM, et al. Immunization with a heat-killed preparation of the environmental bacterium Mycobacterium vaccae promotes stress resilience in mice. Proc Natl Acad Sci. 2016;113(22):E3130-9.

12. Bailey MT, Dowd SE, Galley JD, Hufnagle AR, Rebecca G, Lyte M. Exposure to a social stressor alters the structure of the intestinal microbiota: implications for stressor-induced immunomodulation. Brain Behav Immun. 2011;25:397-407.

13. Bharwani A, Mian MF, Foster JA, Surette MG, Bienenstock J, Forsythe $P$. Structural \& functional consequences of chronic psychosocial stress on the microbiome \& host. Psychoneuroendocrinology. 2016;63:217-27.

14. O'Mahony SM, Marchesi JR, Scully P, Codling C, Ceolho A-M, Quigley EMM, et al. Early life stress alters behavior, immunity, and microbiota in rats: implications for irritable bowel syndrome and psychiatric illnesses. Biol Psychiatry. 2009;65:263-7.

15. Forsythe P, Bienenstock J. Immunomodulation by commensal and probiotic bacteria. Immunol Invest. 2010;39:429-48.

16. Sharon G, Garg N, Debelius J, Knight R, Dorrestein PC, Mazmanian SK. Specialized metabolites from the microbiome in health and disease. Cell Metab. 2014;20:719-30.

17. Sommershof $\mathrm{A}$, Aichinger $\mathrm{H}$, Engler $\mathrm{H}$, Adenauer $\mathrm{H}$, Catani $\mathrm{C}$, Boneberg E-M, et al. Substantial reduction of naive and regulatory $T$ cells following traumatic stress. Brain Behav Immun. 2009;23:1117-24.

18. Berton O, McClung CA, Dileone RJ, Krishnan V, Renthal W, Russo SJ, et al. Essential role of BDNF in the mesolimbic dopamine pathway in social defeat stress. Science. 2006;311:864-8.

19. Krishnan V, Han MH, Graham DL, Berton O, Renthal W, Russo SJ, et al. Molecular adaptations underlying susceptibility and resistance to social defeat in brain reward regions. Cell. 2007;131:391-404.

20. Janik R, Thomason LAM, Stanisz AM, Forsythe P, Bienenstock J, Stanisz GJ. Magnetic resonance spectroscopy reveals oral Lactobacillus promotion of increases in brain GABA, N-acetyl aspartate and glutamate. Neuroimage. 2016;125:988-95.

21. Kunze WA, Mao $Y$, Wang B, Huizinga JD, Ma X, Forsythe $P$, et al. Lactobacillus reuteri enhances excitability of colonic $\mathrm{AH}$ neurons by inhibiting calcium-dependent potassium channel opening. J Cell Mol Med. 2009:13:2261-70

22. Perez-Burgos A, Wang B, Mao Y-K, Mistry B, McVey Neufeld K-A, Bienenstock J, et al. Psychoactive bacteria Lactobacillus rhamnosus (JB-1) elicits rapid frequency facilitation in vagal afferents. Am J Physiol Gastrointest Liver Physiol. 2013;304:G211-20.

23. Karimi K, Kandiah N, Chau J, Bienenstock J, Forsythe P. A Lactobacillus rhamnosus strain induces a heme oxygenase dependent increase in Foxp3 + regulatory T cells. PLoS One. 2012;7:1-12.

24. Karimi K, Inman MD, Bienenstock J, Forsythe P. Lactobacillus reuteri-induced regulatory $T$ cells protect against an allergic airway response in mice. Am J Respir Crit Care Med. 2009;179:186-93.

25. Forsythe P, Wang B, Khambati I, Kunze WA. Systemic effects of ingested lactobacillus rhamnosus: inhibition of mast cell membrane potassium (IKCA) current and degranulation. PLoS One. 2012;7:1-8.

26. Caporaso JG, Kuczynski J, Stombaugh J, Bittinger K, Bushman FD, Costello EK, et al. QIIME allows analysis of high-throughput community sequencing data. Nat Methods. 2010;7:335-6.

27. Bagot RC, Parise EM, Pen CJ, Zhang H, Maze I, Chaudhury D, et al Ventral hippocampal afferents to the nucleus accumbens regulate susceptibility to depression. Nat Commun. 2015;6:7062. doi:10.1038/ ncomms8062

28. Kinsey SG, Bailey MT, Sheridan JF, Padgett DA, Avitsur R. Repeated social defeat causes increased anxiety-like behavior and alters splenocyte function in C57BL/6 and CD-1 mice. Brain Behav Immun Elsevier. 2007;21:458-66.

29. Crawley JN. Exploratory behavior models of anxiety in mice. Neurosci Biobehav Rev. 1985;9:37-44.

30. Bendtsen KMB, Krych L, Sørensen DB, Pang W, Nielsen DS, Josefsen K, et al. Gut Microbiota Composition Is Correlated to Grid Floor Induced Stress and Behavior in the BALB/c Mouse. PLoS One. 2012;7, e46231.
31. Hsiao EY, McBride SW, Hsien S, Sharon G, Hyde ER, McCue T, et al. Microbiota modulate behavioral and physiological abnormalities associated with neurodevelopmental disorders. Cell. 2013;155:1451-63.

32. Tarr AJ, Galley JD, Fisher SE, Chichlowski M, Berg BM, Bailey MT. The prebiotics 3'Sialyllactose and 6'Sialyllactose diminish stressor-induced anxiety-like behavior and colonic microbiota alterations: Evidence for effects on the gut-brain axis. Brain Behav Immun. 2015;50:166-77.

33. Clemente JC, Ursell LK, Parfrey LW, Knight R. The impact of the gut microbiota on human health: an integrative view. Cell. 2012;148:1258-70.

34. Sanderson S, Boardman W, Ciofi C, Gibson R. Human gut microbes associated with obesity. Nature. 2006:444:1022-3.

35. Thompson JA, Oliveira RA, Djukovic A, Ubeda C, Xavier KB. Manipulation of the quorum sensing signal Al-2 affects the antibiotic-treated gut microbiota. Cell Rep. 2015;10:1861-71.

36. Mariat D, Firmesse $O$, Levenez F, Guimarăes V, Sokol H, Doré J, et al. The Firmicutes/Bacteroidetes ratio of the human microbiota changes with age. BMC Microbiol. 2009:9:123.

37. Mayer EA. The neurobiology of stress and gastrointestinal disease. Gut. 2000:47:861-9.

38. Perez-Burgos A, Mao Y-K, Bienenstock J, Kunze WA. The gut-brain axis rewired: adding a functional vagal nicotinic "sensory synapse". FASEB J. 2014;28:3064-74.

39. Gębicki J, Sysa-Jędrzejowska A, Adamus J, Woźniacka A, Rybak M, Zielonka J. 1-Methylnicotinamide: a potent anti-inflammatory agent of vitamin origin. Pol J Pharmacol. 2003;55:109-12.

40. Maitre M, Humbert J-P, Kemmel V, Aunis D, Andriamampandry C. A mechanism for gamma-hydroxybutyrate (GHB) as a drug and a substance of abuse. Med Sci (Paris). 2005;21:284-9.

41. Castelli MP, Ferraro L, Mocci I, Carta F, Carai MAM, Antonelli T, et al. Selective $\gamma$-hydroxybutyric acid receptor ligands increase extracellular glutamate in the hippocampus, but fail to activate $\mathrm{G}$ protein and to produce the sedative/hypnotic effect of $\gamma$-hydroxybutyric acid. J Neurochem. 2003;87:722-32.

42. Gobaille S, Schleef C, Hechler V, Viry S, Aunis D, Maitre M. Gammahydroxybutyrate increases tryptophan availability and potentiates serotonin turnover in rat brain. Life Sci. 2002;70:2101-12.

43. Mundorf ML, Hochstetler SE, Wightman RM. Amine weak bases disrupt vesicular storage and promote exocytosis in chromaffin cells. J Neurochem. 1999;73:2397-405.

44. Schönfeld $C-L$, Trendelenburg $U$. The release of $3 \mathrm{H}$-noradrenaline by $\mathrm{p}$-and m-tyramines and-octopamines, and the effect of deuterium substitution in a-position. Naunyn Schmiedebergs Arch Pharmacol. 1989:339:433-40.

45. Fuchs D, Möller AA, Reibnegger G, Stöckle E, Werner ER, Wachter H. Decreased serum tryptophan in patients with HIV-1 infection correlates with increased serum neopterin and with neurologic/psychiatric symptoms. J Acquir Immune Defic Syndr. 1990;3:873-6.

46. Werner-Felmayer G, Werner ER, Fuchs D, Hausen A, Reibnegger G, Wachter $H$. Characteristics of interferon induced tryptophan metabolism in human cells in vitro. Biochim Biophys Acta. 1989;1012:140-7.

47. Ramos A, Mormède P. Stress and emotionality: a multidimensional and genetic approach. Neurosci Biobehav Rev. 1997;22:33-57.

48. Kelly JR, Allen AP, Temko A, Hutch W, Kennedy PJ, Farid N, et al. Lost in translation? The potential psychobiotic Lactobacillus rhamnosus (JB-1) fails to modulate stress or cognitive performance in healthy male subjects. Brain Behav Immun. 2016. http://dx.doi.org/10.1016/j.bbi.2016. 11.018 .

49. Serretti A, Calati R, Goracci A, Di Simplicio M, Castrogiovanni P, De Ronchi D. Antidepressants in healthy subjects: what are the psychotropic/ psychological effects? Eur Neuropsychopharmacol. 2010;20:433-53.

50. Huhman KL, Solomon MB, Janicki M, Harmon AC, Lin SM, Israel JE, et al. Conditioned defeat in male and female Syrian hamsters. Horm Behav. 2003:44:293-9

51. American Psychiatric Association. Diagnostic and statistical manual of mental disorders. 5th ed. Washington, DC: American Psychiatric Association; 2013.

52. Liu Z-H, Smith CB. Dissociation of social and nonsocial anxiety in a mouse model of fragile X syndrome. Neurosci Lett. 2009;454:62-6.

53. Groux H, O'Garra A, Bigler M, Rouleau M, Antonenko S, de Vries JE, et al. A CD4+ T-cell subset inhibits antigen-specific T-cell responses and prevents colitis. Nature. 1997;389:737-42. 
54. Lindqvist D, Wolkowitz OM, Mellon S, Yehuda R, Flory JD, Henn-Haase C, et al. Proinflammatory milieu in combat-related PTSD is independent of depression and early life stress. Brain Behav Immun. 2014;42:81-8.

55. Dantzer R, O'Connor JC, Freund GG, Johnson RW, Kelley KW. From inflammation to sickness and depression: when the immune system subjugates the brain. Nat Rev Neurosci. 2008;9:46-56.

56. Wohleb ES, Powell ND, Godbout JP, Sheridan JF. Stress-induced recruitment of bone marrow-derived monocytes to the brain promotes anxiety-like behavior. J Neurosci. 2013;33:13820-33.

57. Cámara RJA, Gander M-L, Begré S, Von Känel R, Group SIBDCS. Posttraumatic stress in Crohn's disease and its association with disease activity. Frontline Gastroenterol. 2011;2:2-9.

58. Wohleb ES, McKim DB, Sheridan JF, Godbout JP. Monocyte trafficking to the brain with stress and inflammation: a novel axis of immune-tobrain communication that influences mood and behavior. Front Neurosci. 2015;8:1-17.

59. O'Garra A, Vieira PL, Vieira P, Goldfeld AE. IL-10-producing and naturally occurring CD4+ Tregs: limiting collateral damage. J Clin Invest. 2004;114: 1372-8.

60. Bruce-Keller AJ, Salbaum JM, Luo M, Blanchard E, Taylor CM, Welsh DA, et al. Obese-type gut microbiota induce neurobehavioral changes in the absence of obesity. Biol Psychiatry. 2014;77:607-15.

61. Buffington SA, Viana G, Prisco D, Auchtung TA, Ajami NJ, Petrosino JF, et al. Microbial reconstitution reverses maternal diet-induced social and synaptic deficits in offspring. Cell. 2016;165:1762-75.

62. Eloe-fadrosh EA, Brady A, Crabtree J, Drabek EF, Ma B, Mahurkar A, et al. Functional dynamics of the gut microbiome in elderly people during probiotic consumption. MBio. 2015;6:e00231-15.

63. Zucchi R, Chiellini G, Scanlan TS, Grandy DK. Trace amine-associated receptors and their ligands. Br J Pharmacol. 2006;149:967-78.

64. Kidd M, Modlin IM, Gustafsson BI, Drozdov I, Hauso O, Pfragner R. Luminal regulation of normal and neoplastic human EC cell serotonin release is mediated by bile salts, amines, tastants, and olfactants. Am J Physiol Gastrointest Liver Physiol. 2008;295:G260-72

65. Yano JM, Yu K, Donaldson GP, Shastri GG, Ann P, Ma L, et al. Indigenous bacteria from the gut microbiota regulate host serotonin biosynthesis. Cell. 2015:161:264-76.

66. Patterson E, Cryan JF, Fitzgerald GF, Ross RP, Dinan TG, Stanton C. Gut microbiota, the pharmabiotics they produce and host health. Proc Nutr Soc. 2014;73:477-89.

67. David LA, Materna AC, Friedman J, Campos-Baptista MI, Blackburn MC, Perrotta A, et al. Host lifestyle affects human microbiota on daily timescales. Genome Biol. 2014;15:R89.

68. Korpela K, Salonen A, Virta LJ, Kekkonen RA, Forslund K, Bork P, et al. Intestinal microbiome is related to lifetime antibiotic use in Finnish pre-school children. Nat Commun Nature Publishing Group. 2016;7:10410. doi:10.1038/ncomms10410

69. Zhernakova A, Kurilshikov A, Bonder MJ, Tigchelaar EF, Schirmer M, Vatanen T, et al. Population-based metagenomics analysis reveals markers for gut microbiome composition and diversity. Science. 2016:352:565-9.

70. Gilbert JA, Quinn RA, Debelius J, Xu ZZ, Morton J, Garg N, et al. Microbiome-wide association studies link dynamic microbial consortia to disease. Nature. 2016;535:94-103.

71. Costello EK, Lauber CL, Hamady M, Fierer N, Gordon Jl, Knight R. Bacterial community variation in human body habitats across space and time. Science. 2009;326:1694-7.

72. Lay C, Rigottier-Gois L, Holmstrøm K, Rajilic M, Vaughan EE, de Vos WM, et al. Colonic microbiota signatures across five northern European countries. Appl Environ Microbiol. 2005;71:4153-5.

73. Eckburg PB, Bik EM, Bernstein CN, Purdom E, Dethlefsen L, Sargent M, et al. Diversity of the human intestinal microbial flora. Science. 2005:308:1635-8.

\section{Submit your next manuscript to BioMed Central and we will help you at every step:}

- We accept pre-submission inquiries

- Our selector tool helps you to find the most relevant journal

- We provide round the clock customer support

- Convenient online submission

- Thorough peer review

- Inclusion in PubMed and all major indexing services

- Maximum visibility for your research

Submit your manuscript at www.biomedcentral.com/submit
) Biomed Central 